\title{
ORIGENS SOCIAIS DOS FUTUROS EDUCADORES: A DEMOCRATIZAÇÃO DESIGUAL DA EDUCAÇÃO SUPERIOR
}

\author{
JANETE PALAZZO* \\ CAndido Alberto Gomes**
}

Recebido: 15 set. 2011

Aprovado: 18 jun. 2012

* Doutoranda em Educação pela Universidade Católica de Brasília (UCB). Vice-diretora da Faculdade de Ciências Sociais e Tecnológicas (FACITEC/DF). E-mail: janete@facitec.br.; janjanpalazzo@yahoo.com.br ** Doutor em Educação pela Universidade da Califórnia, Los Angeles. Cátedra UNESCO de Juventude, Educação e Sociedade da Universidade Católica de Brasília. E-mail: clgomes@terra.com.br

Resumo: O objetivo deste artigo é comparar, por meio de um estudo de caso, as características sociais, econômicas e culturais de alunos de cursos de formação de educadores e de Direito, ramo historicamente mais seletivo e, por isso, detentor de maior valorização social. Assim, pretende-se verificar a existência de diferenças sociais entre os estudantes desses cursos, no âmbito da instituição, apesar da expansão da educação superior no Brasil. A literatura constata que o crescimento das matrículas tem conduzido a uma democratização "estratificada", em que carreiras mais seletivas continuam como tal, enquanto as demais se tornam mais acessíveis a estudantes de origens sociais menos favorecidas. A pesquisa exploratória utilizou questionários como instrumentos de coleta de dados, respondidos por estudantes ingressantes do primeiro e segundo semestres de Pedagogia, Matemática e Direito em uma instituição privada de educação superior do Distrito Federal. Os resultados indicaram que os futuros educadores têm origem em estratos socioeconômicos menos privilegiados e são detentores de menos capital cultural, ao contrário do grupo de Direito. Ademais, os custos diretos e indiretos dos licenciandos são menores que a metade dos de Direito e, pela sua renda, recebem mais bolsas de estudo. Assim, pessoas com status socioeconômico mais alto tendem a ingressar em cursos e instituições de mais alto prestígio, situação acentuada com a inflação educacional, isto é, a desvalorização progressiva dos diplomas ante o crescimento do número de graduados. Com isso, visam a ter melhores oportunidades ocupacionais, mantendo até certo ponto as diferenças sociais. Quanto aos futuros educadores, indaga-se sobre as implicações da formação de profissionais, cujos custos e retornos da formação são modestos.

Palavras-chave: Educação superior. Magistério. Estratificação social. Democratização educacional. Custos educacionais.

\section{SOCIAL ORIGINS OF PROSPECTIVE TEACHERS: \\ THE UNEQUAL DEMOCRATIZATION OF HIGHER EDUCATION}

Abstract: The aim of this paper is to compare, through a case study, the social, economic and cultural characteristics between teacher education students and Law students, an area historically more selective and that, therefore, holds greater social value. It aims to characterize the social differences of these undergraduate programs within a college, despite the expansion of higher education in Brazil. The literature highlights that the growth in enrollment has led to a stratified "democratization", by which more selective careers continue being elitist, whereas the others become more accessible to students from disadvantaged social backgrounds. This exploratory project applied questionnaires to students of both groups in their first and second terms at a private college located in the Federal District. The results indicated that prospective teachers come from less privileged socioeconomic 


\begin{abstract}
strata and hold less cultural capital, unlike the group of Law students. Furthermore, the total direct and indirect education costs of the former was about $50 \%$ of those of their Law colleagues. As a result of their low income, teacher program students were granted more scholarships. Therefore, people with higher socioeconomic status tend to apply and to enroll in higher prestige programs and colleges. These differences tend to be magnified by educational inflations, i.e., the devaluation of the diploma due to the increase in the number of graduates. As a consequence, they tend to obtain higher level occupational positions and earnings, maintaining differences in social mobility. As for prospective teachers, this work discusses implications of recruiting lower socio-economic status students, whose education costs and return are both relatively lower.
\end{abstract}

Key words: Higher education. Schoolteachers. Social stratification. Educational democratization. Education costs.

\title{
1 INTRODUÇÃO
}

A educação superior vem apresentando grande expansão desde a década de 1970, em número de matrículas (DIAS SOBRINHO, 2010; BARREYRO, 2008; MOEHLECKE; CATANI, 2006). Antes disso, esse nível de ensino, em especial oferecido pela universidade pública, era restrito a uma elite de melhor formação escolar prévia, composta pela nova classe média (DURHAM, 2005). Segundo Durham, a explicação para o aumento na demanda pela educação superior associa-se ao enriquecimento e ampliação da classe média, decorrentes do período de desenvolvimento econômico por que passou o Brasil, e às novas oportunidades ocupacionais para setores mais modernos da economia e da tecnoburocracia estatal.

Desde o início do regime militar, observa-se um aumento na demanda pela educação superior, tanto no setor público como no privado. A década de 1970 apresentou uma crescente elevação da procura por um curso superior. Os anos 1980 foram marcados por uma estagnação no crescimento observado no período anterior, que continuou nos anos 1990, tanto no número de instituições de educação superior (IES) quanto em quantidade de matrículas. Entretanto, foi a partir de 1995, na primeira presidência do Sr. Fernando Henrique Cardoso, que as IES privadas se expandiram de forma ainda mais acelerada (BARREYRO, 2008). Dados do Censo da Educação Superior de 2009 revelam que as de instituições de ensino superior privadas representam $89,4 \%$ das IES brasileiras, demonstrando que o setor vem se consolidando nos últimos anos. O gráfico 1 mostra a evolução do número de matrículas na educação superior brasileira desde 1962. Ressalta-se que os dados desagregados por dependência administrativa (pública e privada) estavam disponíveis apenas a partir de 1980 . 


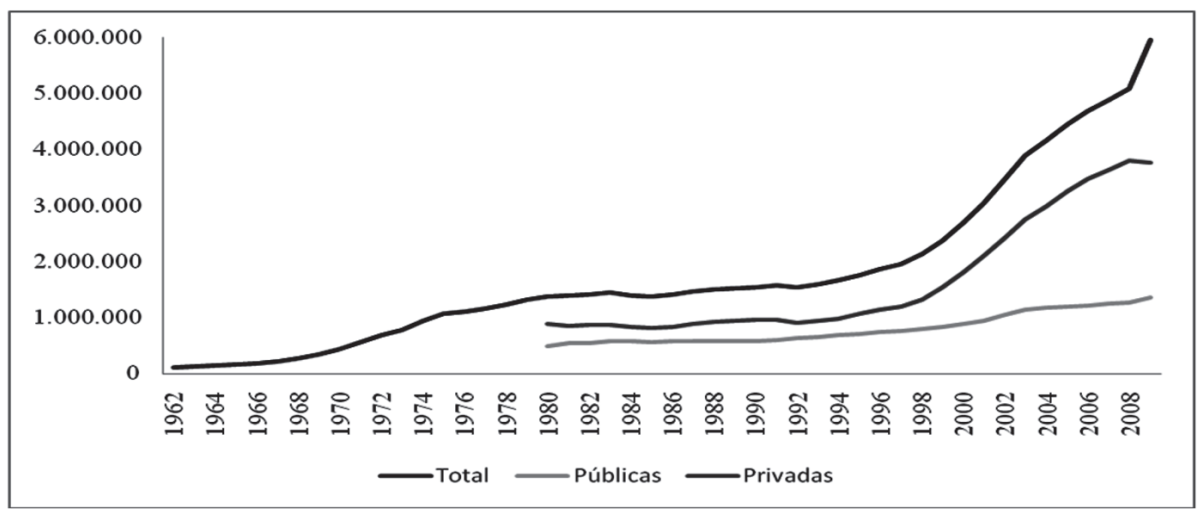

Fonte: INEP (1999, 2008, 2009a, 2009b, 2010, 2011).

O gráfico 1 mostra como as matrículas na educação superior brasileira, especialmente no setor privado, cresceram nos últimos anos. Essa expansão justifica-se pela tentativa de cumprimento da meta do Plano Nacional de Educação (BRASIL, 2001), de, até o final de 2010, inserir na educação superior pelo menos 30,0\% dos jovens de 18 a 24 anos. Entretanto, estudo revela que, em 2007, apenas 13,1\% desse público frequentava a educação superior (IBGE, 2008). Ou seja, ainda é preciso muito esforço do Estado e da sociedade para alcançar a meta estabelecida.

Mesmo com o crescente acesso à educação superior, comprovando que o país tem ampliado o acesso à escolarização em geral, continua a haver amplas desigualdades referentes à qualidade da educação e ao grau de democratização (GOMES, 2010a). Dados do Censo da Educação Superior de 2009 (INEP, 2011) indicam que a média de candidatos por vaga nas instituições públicas foi 6,57 , enquanto para as IES privadas foi 1,31, sugerindo maior seletividade das primeiras. Assim, a tendência é de os mais aquinhoados se classificarem para os cursos mais prestigiados das IES mais requisitadas. Os menos favorecidos, por sua vez, ocupam as vagas dos cursos mais acessíveis das IES menos concorridas. Nesse sentido, a democratização se faz paulatinamente, preenchendo ao mesmo tempo duas hierarquias conjugadas de escaninhos: a de cursos e a de IES. Esta lenta mudança pode ser relacionada à consciência conservadora no Brasil (MERCADANTE, 1965), que guia as mudanças no sentido da lentidão e, se possível, da continuidade.

É neste contexto que se insere o presente artigo, cujo objetivo é comparar as características sociais, econômicas e culturais entre alunos ingressantes dos 
cursos de licenciatura e de um curso mais seletivo, detentor de maior valorização social. Desse modo, pretende-se verificar se, apesar da "democratização" do acesso à educação superior, as diferenças entre cursos na mesma IES espelham diferenças sociais do corpo discente. Na IES pesquisada, o curso mais concorrido no processo seletivo era Direito, um dos motivos pelo qual foi escolhido para comparar com as licenciaturas.

\section{A DEMOCRATIZAÇÃO DESIGUAL DA EDUCAÇÃO SUPERIOR}

Ainda no ensino médio, observa-se que as diferenças nas opções oferecidas apresentam uma hierarquia de status ou de prestígio, de modo que os cursos mais compensadores são frequentados por alunos de nível socioeconômico mais elevado (GOUVEIA, 1981; RIBEIRO; KLEIN, 1982; GOMES, 1988, 2005, 2010a). Da mesma forma, no momento de escolha de um curso superior, percebe-se prévio grau de seletividade, visto que, para cursos de maior prestígio social e, potencialmente, de maiores recompensas financeiras, há uma grande concentração de candidatos de mais alto nível socioeconômico. Por outro lado, verifica-se que os cursos de menor prestígio social tendem a ser mais procurados por concorrentes de origens sociais mais modestas (BRAGA; PEIXOTO; BOGUTCHI, 2001; BORGES; CARNIELLI, 2005; VARGAS, 2010; DINIZPEREIRA, 2011), sugerindo, assim, que a seletividade escolar está relacionada à seletividade social (BORGES; CARNIELLI, 2005).

Para Bourdieu (2007a), os resultados das seleções diretas ou indiretas para acesso à educação superior gerarão, durante todo o percurso acadêmico, rigores desiguais para os indivíduos das diferentes classes sociais. Além disso, a baixa qualidade da educação corresponde a um círculo vicioso, em que mal formados se tornam mal formadores, que geram outros mal formados e formadores (GOMES, 2010a).

A elevada demanda por cursos de alto prestígio social, nomeadamente Direito, Engenharia e Medicina, pode ser explicada historicamente. Fernando de Azevedo (1996) afirmou que a escolha das profissões tinha como objetivo elevar o indivíduo a cargos nobres, de preferência com o exercício de atividades intelectuais, de modo a suprir a propriedade da terra e os privilégios de nascimento. As profissões liberais serviam como um elevador social, enquanto as atividades manuais e mecânicas eram reservadas a camadas sociais inferiores da população. A atratividade dessas ocupações explicava-se mais por sua influência social do que pela vocação ou por tendências individuais. Ainda hoje, 
as profissões de médico, engenheiro e advogado são chamadas "tradicionais" (DINIZ, 2001) ou "imperiais", pelo fato de terem sido constituídas durante o Império (COELHO, 1999), numa época em que a preocupação do país era formar profissionais necessários ao Estado e à elite local (DURHAM, 2005).

Em uma tentativa de classificação dos cursos superiores, segundo critérios sociais e acadêmicos dos estudantes dos cursos de Humanidades da Universidade de São Paulo, e conforme os conceitos de capital econômico, social e cultural de Bourdieu, Setton (1999) criou três classes de cursos: os seletos, os intermediários e os populares. Os cursos seletos incluem, entre outros: Direito, Administração, Arquitetura, Psicologia e Relações Públicas. Os cursos intermediários são os de Turismo, Contabilidade, Jornalismo, Publicidade e outros. Entre os populares, estão: Biblioteconomia, Pedagogia, Geografia, Letras, História, Filosofia, Ciências Sociais e Contabilidade, sobre o que se pode concluir que as licenciaturas em geral estão enquadradas nessa classificação. A autora explicou que o critério para classificar os cursos como populares foi a baixa concentração nos três indicadores estudados: capital econômico, social e cultural. Algumas características identificadas entre os cursos populares foram: a baixa concorrência no processo seletivo, pouca valorização das carreiras, expectativas de baixos salários e carência de oportunidades de emprego em postos de alto prestígio social.

Conforme Tartuce, Nunes e Almeida (2010), além da diminuição da demanda pelos cursos de licenciatura e da quantidade de concluintes, observa-se mudança no perfil do público que procura esses cursos. Segundo Navarro (2002) e Rama e Navarro (2004), nos últimos anos tem havido mudança do recrutamento de professores para estratos sociais de menor renda e menos educação formal. Em pesquisa para identificar o perfil socioeconômico dos professores da América Latina, esses autores identificaram que estudantes das carreiras da educação tendiam a apresentar antecedentes socioeconômicos inferiores aos de outras carreiras superiores.

Essa tendência foi confirmada por Gatti e Barreto (2009) na análise dos dados do Exame Nacional de Desempenho dos Estudantes (ENADE) de 2005. As pesquisadoras verificaram que a maioria dos alunos $(50,4 \%)$ dos cursos de formação de professores estava concentrada nas faixas de renda familiar média, com intervalo de três a dez salários mínimos, situação confirmada por Diniz-Pereira (2011). Observou-se que 39,2\% dos alunos tinham renda familiar de até três salários mínimos e era inexpressiva a frequência de estudantes em faixas mais elevadas de renda. Concluíram, ainda, que a origem dos docentes estava em setores e famílias com menos capital cultural e econômico (VAIL- 
LANT, 2004). Louzano e colaboradores (2010) corroboraram estes resultados, ao constatarem que o Brasil atrai para os programas de formação de professores pessoas com baixo rendimento acadêmico e perfil socioeconômico mais baixo.

No Brasil, pesquisa da UNESCO (2004) identificou as características sociais, econômicas e profissionais dos docentes de ensino fundamental e médio. Um dos resultados foi que a maioria dos professores declarou renda familiar entre dois e dez salários mínimos. Não obstante, verificou diferença entre a renda familiar dos professores titulados com ensino médio e a dos que tinham nível superior, bem como diferenças evidentes entre os professores atuantes nas regiões Norte-Nordeste e Sudeste, de modo que os primeiros apresentavam renda bem inferior.

Ainda sobre o perfil socioeconômico dos estudantes de magistério, Brito (2007), ao analisar dados do ENADE 2005, pesquisou as características predominantes dos estudantes de licenciaturas. No perfil traçado, verificou que $39,8 \%$ das famílias deles ganhavam até três salários mínimos. Os pais, na proporção de 59,2\%, haviam concluído o ensino fundamental e as mães, $56,0 \%$. Quase metade dos estudantes tinha conhecimento praticamente nulo de línguas inglesa $(46,4 \%)$ e espanhola (42,8\%). Quanto aos jornais, $72,1 \%$ liam apenas ocasionalmente. Esses dados parecem indicar menos capital cultural por parte dos estudantes de cursos para formação de professores.

Historicamente, a profissão docente gozava de certo status social, mas perdeu esse prestígio ao longo do tempo, pois se alterou o papel tradicional dos docentes. Juntamente com os párocos, os professores do ensino primário eram os únicos agentes propagadores das culturas nas aldeias e vilas da província (NÓVOA, 1999; JESUS, 2004). Os professores do ensino secundário eram o espelho literário e científico em que se fundamentava a cultura de várias cidades (ESTEVE, 1999). Nessa época, prevaleciam os valores intelectuais e humanistas. Hoje, ao contrário, predominam os valores individualistas e economicistas, inclusive fomentados pelos meios de comunicação (JESUS, 2004). Ou seja, as profissões mais valorizadas socialmente tendem a ser aquelas associadas ao recebimento de altos salários, conduzindo à perda de prestígio social do magistério. Entretanto, os professores não conseguiram substituir essas imagens por novas representações profissionais (NÓVOA, 2009).

É imprescindível ressaltar a importância social e econômica do professor, pois a profissão docente é a base para o desenvolvimento de qualquer outra profissão. Tardif e Lessard (2009, p. 7) argumentam que o ensino escolar "possui uma espécie de proeminência sobre outras esferas de ação", já que quase todos os profissionais precisaram ser instruídos antes de ser o que são e para fazer o que 
fazem. Além disso, é possível afirmar que grande parte da população brasileira que aprendeu a ler, escrever e contar no último século passou pela escola e foi assistida por esses profissionais, cujo ofício é ensinar (SOUSA NETO, 2005). A docência constitui-se, assim, um dos mais importantes e numerosos grupos ocupacionais, essencial para o crescimento da economia das sociedades modernas (TARDIF; LESSARD, 2009; GATTI; BARRETO, 2009).

\section{OS POSSÍVEIS EFEITOS DA INFLAÇÃO EDUCACIONAL}

Ao mesmo tempo em que se verifica a elevação da média de escolaridade da população nas últimas décadas, crescem também as exigências de escolaridade para o trabalho (SINGER, 1986; DURU-BELLAT, 2006; GOMES et al, 2006). Trata-se da inflação educacional, chamada por Singer (1986) de "crise da escola", ou seja, quando "a abundância relativa de credenciais leva à sua própria desvalorização" (GOMES, 2010b, p. 338), contrariando, dessa forma, a versão tradicional da teoria do capital humano. Com o incremento dos trabalhadores com credenciais escolares mais elevadas, a graduação deixa de ser um diferencial competitivo, levando a um aumento do grau de exigência do mundo do trabalho, por exemplo, quando "pessoas superqualificadas recebem salários menores, por se situarem em cargos de níveis mais modestos" (GOMES, 2010a, p. 66), ou quando as titulações não correspondem aos cargos ocupados (CORADINI, 2010).

Como afirmou Bourdieu (2007c), um diploma é desvalorizado sempre que o crescimento da quantidade de seus portadores é mais rápido que o crescimento da quantidade de cargos a que esses diplomas conduziam no início do período, de forma que as principais vítimas desse processo são os que não dispõem das credenciais. Essa inflação educacional pode ser traduzida como uma espécie de freio à mobilidade social ascendente. Aliás, à medida que as credenciais aumentam, há um risco futuro de mobilidade descendente (PEUGNY, 2009).

Por outro lado, há uma tendência de os antigos portadores desses diplomas elevarem suas credenciais a níveis cada vez mais altos, raros e seletivos (inclusive buscando a internacionalização de suas experiências educacionais), a fim de manter e/ou melhorar suas posições no mundo do trabalho (NOGUEIRA; AGUIAR; RAMOS, 2008). Desse modo, as desigualdades sociais, culturais e escolares permaneceriam e se reconstruiriam, porém em níveis cada vez mais elevados. Segundo Schwartzman (2004, p. 154), cria-se, então, "um círculo de autoperpetuação da estratificação e da discriminação social”. 
Ainda de acordo com Bourdieu (2007c), a inflação educacional gera uma defasagem entre as aspirações produzidas pelo sistema educacional e as oportunidades efetivamente oferecidas. Dessa forma, grandes serão as frustrações dos jovens que buscam no diploma um impulsor para ascender socialmente $\mathrm{e}$ não alcançam tal objetivo. Trata-se do processo de desintegração da promessa integradora da escola (GENTILI, 2008).

As desigualdades na democratização da educação superior, em que as pessoas de nível socioeconômico mais elevado tendem a ingressar em cursos e instituições de mais alto prestígio e vice-versa, é acentuada no período da crise da inflação educacional. Certamente, terão maiores oportunidades de obter trabalho compatível com os portadores de credenciais educacionais mais valorizadas, ou seja, aquelas originárias de cursos e IES de mais alto prestígio social, tornando-se um microcosmo parcial das diferenças sociais.

\section{METODOLOGIA}

A pesquisa realizada teve caráter exploratório. A amostra foi constituída por alunos ingressantes do $2^{\circ}$. semestre de 2010 e $1^{\circ}$. semestre de 2011 nos cursos de Licenciatura em Matemática e Pedagogia e no curso de Direito de uma IES particular de porte médio, no Distrito Federal. Como se trata de apenas uma IES, os resultados encontrados não podem ser generalizados para o Distrito Federal ou para o país.

Os questionários para levantamento do perfil socioeconômico e cultural dos alunos foram aplicados no mês de abril de 2011. Foram respondentes 176 alunos do curso de Direito, 42 de Matemática e 144 de Pedagogia, o que totalizou 362 questionários. Ressalta-se que os dados dos cursos de Matemática e de Pedagogia foram tratados em conjunto, por serem cursos para formar educadores. No curso de Direito, os respondentes concentravam-se no curso noturno $(55,7 \%)$. Já nas licenciaturas, essa proporção era bem maior: $64,0 \%$ dos pesquisados estudava à noite.

\section{O PERFIL DOS FUTUROS EDUCADORES E ADVOGADOS}

Sabe-se que a profissão docente tem sido predominantemente feminina (GOUVEIA, 1970). Nos cursos para educadores, mantém-se esta tendência. No grupo pesquisado nos cursos de Pedagogia e Matemática, 82,7\% eram mulheres. Quanto ao curso de Direito, dos 176 alunos pesquisados, 55,7\% eram mulheres e 44,3\%, homens, uma distribuição relativamente equilibrada. 
Em relação à média de idade dos participantes da pesquisa, a diferença entre os cursos foi de quase um ano. A média dos alunos de Licenciatura era 26,0 anos (desvio padrão - DP, de 7,4), enquanto para Direito, obteve-se a média de 27,0 anos (DP 8,9). Uma possível explicação para a mais alta média de dos estudantes de Direito e o correspondente desvio padrão é o fato de $19,9 \%$ dos respondentes desse curso já terem formação de nível superior.

Quanto ao estado civil dos respondentes, os resultados foram semelhantes nos dois grupos. Eram solteiros $66,1 \%$ dos estudantes de Direito e $65,1 \%$ dos licenciandos, o que justifica o fato de pouco mais de $30,0 \%$ dos alunos em ambos os cursos não trabalharem ou terem seus gastos financiados pela família. Os casados representavam 29,2\% dos alunos de Direito e 28,5\% dos estudantes de Pedagogia e Matemática. Quanto à cor, a maioria dos estudantes de licenciatura se declarou parda/mulata $(46,2 \%)$ ou branca $(37,1 \%)$. Os negros constituíam $11,8 \%$ do público pesquisado. No curso de Direito, os brancos prevaleciam $(45,5 \%)$ e havia $40,3 \%$ de pardos/mulatos e $9,7 \%$ de negros.

Para atribuir uma classificação econômica à família de cada respondente, foi utilizado o Critério de Classificação Econômica Brasil da Associação Brasileira de Empresas de Pesquisa (2009). São atribuídos determinados pontos em relação à disponibilidade e quantidade de certos itens domiciliares (televisão em cores, rádio, banheiro, automóvel, empregada mensalista, máquina de lavar, videocassete e/ou DVD, geladeira e freezer) e ao grau de escolaridade do chefe de família. A pontuação total gera, então, os seguintes estratos de classificação econômica: A1, A2, B1, B2, C1, C2, D e E. Os respondentes que não atribuíram resposta ao grau de escolaridade do pai tiveram a escolaridade da mãe considerada para o cálculo. O gráfico 2 apresenta a distribuição dos estudantes conforme a faixa econômica da família.

\section{Gráfico 2 - Faixas econômicas dos alunos de Direito e dos cursos de Licenciatura}

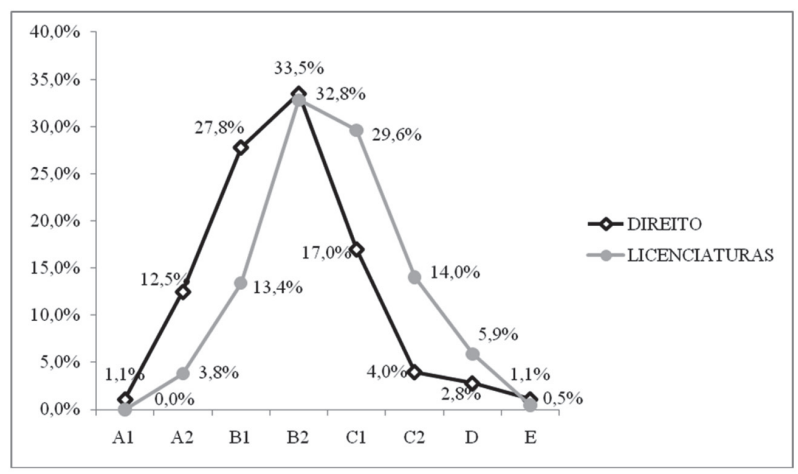

Fonte:Pesquisa de campo (2011). 
Observa-se que, tanto nos cursos de Licenciatura quanto no de Direito, a maioria dos alunos concentrava-se na faixa B2. Entretanto, a distribuição demonstra que as faixas superiores a B2 são ocupadas, em maior parte, por alunos do curso de Direito, enquanto nas faixas inferiores a B2 se situam os estudantes de Licenciaturas. De acordo com os critérios de pontuação estabelecidos pela $\mathrm{ABEP}$, a renda média bruta familiar dos alocados na faixa $\mathrm{B} 2$, no ano de 2009 , era $\mathrm{R} \$ 2.656,00$. Nos extremos, tem-se a renda média de $\mathrm{R} \$ 11.480,00$ para a faixa $A 1$ e $R \$ 415,00$ para a faixa $E$.

As faixas econômicas estabelecidas com base nos critérios da ABEP podem ser corroboradas pela renda bruta mensal do grupo familiar. Observou-se que $46,2 \%$ dos estudantes dos cursos de Licenciatura declarou renda familiar mensal de até 3 salários mínimos; 43,5\% tinham renda acima de 3 e até 10 salários mínimos, isto é, $89,7 \%$ dos estudantes desses cursos tinham grupos familiares cuja renda não ultrapassava $\mathrm{R} \$ 5.300,00$ (valor referente ao ano de 2010). Quanto aos alunos de Direito, 18,8\% tinham renda familiar mensal de até 3 salários mínimos e 39,2\%, mais de 3 e até 10 salários mínimos. Os estudantes cuja família atingia renda mensal acima de 10 e até 20 salários mínimos representavam 29,0\% no curso de Direito e 7,0\% nas licenciaturas. Verifica-se, assim, uma grande desigualdade de renda entre os grupos pesquisados.

Estes dados aproximaram-se da renda bruta declarada pelos respondentes, diferenciando-se por considerar apenas a sua própria renda, em vez da renda da família, como o critério da $\mathrm{ABEP}$ ou da questão direcionada à renda familiar. Foram feitos dois cálculos para a média de renda bruta mensal do estudante. O primeiro considerou renda igual a zero aos estudantes que declararam não trabalhar (30,1\% de Direito e 30,6\% de Matemática e Pedagogia). Os resultados foram, para os alunos de Direito, uma renda bruta média de R $\$ 2.178,82$ (DP 3167,86 ) e, para os licenciandos, R $\$ 719,68$ (DP 1178,36). A segunda fórmula considerou apenas os estudantes que trabalhavam. Nesse caso, chegou-se à média mensal de $\mathrm{R} \$ 3.208,81$ (DP 3389,82) para os de Direito e $\mathrm{R} \$ 1.073,21$ (DP 1301,50) para as licenciaturas. Em ambas as estimativas, observa-se uma renda mais de $200,0 \%$ inferior dos futuros educadores em relação ao outro grupo. De qualquer modo, é preciso analisar estes dados com cautela, pois, como o questionário era identificado a fim de possibilitar o acompanhamento dos estudantes ao longo da sua trajetória, é possível que nem todos tenham respondido conforme a realidade.

Esse retrato da renda média dos estudantes do curso de Direito provavelmente os seguirá durante toda a sua vida profissional. Com efeito, Neri (2008), com base na Pesquisa Nacional por Amostra de Domicílios 
(PNAD), calculou os salários médios de 289 ocupações. O primeiro lugar era ocupado por juízes e desembargadores $(\mathrm{R} \$ 13.956,00)$, seguido por diretores gerais $(\mathrm{R} \$ 7371,40)$, médicos $(\mathrm{R} \$ 7.029,00)$, engenheiros ( $\mathrm{R} \$ 4.266,70)$ e advogados ( $\mathrm{R} \$ 3.009,10)$. Os professores de ensino médio ocupavam a posição 55 no ranking $(\mathrm{R} \$ 1.639,20)$. Entretanto, docentes da educação infantil estavam em $101^{\circ}$ lugar (R\$1.145,20).

Esses dados corroboram a supremacia das "profissões imperiais" (Direito, Engenharia e Medicina) no Brasil, associadas ao recebimento dos mais altos salários, sendo, por isso, as profissões mais valorizadas socialmente. Por sua vez, a profissão docente, cujo salário médio, se comparado ao dos juízes e desembargadores, representa apenas 8,1\% desse, figura entre as profissões de nível superior com os menores salários no país. Mesmo com a desvalorização social da profissão do magistério, $74,2 \%$ dos respondentes de licenciatura queriam ser professores e $48,5 \%$ vincularam o principal motivo da opção pelo curso ao desejo de ser professor. Por outro lado, $11,6 \%$ escolheram a licenciatura porque não conseguiram fazer o curso que realmente queriam. No caso dos alunos de Direito, 28,4\% responderam que o principal motivo para escolha do curso foi a possibilidade de aprovação em concurso público, 18,8\%, para conhecer mais sobre seus próprios direitos e $15,7 \%$, devido ao prestígio social proporcionado pelo curso.

Outra diferença verificada entre os grupos pesquisados está na escolaridade dos genitores. A partir da análise da tabela 1, verifica-se que, em uma proporção média (pai e mãe) de $76,0 \%$, os alunos de Direito superaram a escolaridade dos pais. Quanto aos estudantes de Licenciatura, esse percentual foi de $90,0 \%$, caracterizando, dessa forma, a mobilidade intergeracional. Esse fato pode também estar associado à grande expansão da educação superior nos últimos anos, isto é, a geração anterior não tinha as mesmas oportunidades (e por que não dizer exigências ocupacionais?) de fazer um curso superior como a geração atual.

A presente pesquisa apurou ainda os custos médios dos alunos, compreendendo as mensalidades escolares (diretos) e outros custos, indiretos, no semestre da coleta de dados, além de estimar o custo médio total de cada curso (tabela 2). O percentual das mensalidades foi o mesmo para ambos os grupos, entretanto, os valores das licenciaturas foram quase a metade dos de Direito, com pequenas variações percentuais nos custos indiretos. Os custos com transporte e os livros foram muito maiores em termos absolutos e um pouco mais altos percentualmente para os respondentes de Direito. Coincidentemente, os custos 
de cópias dos estudantes de licenciatura em percentuais foram quase o dobro dos de Direito, apresentando os primeiros uma dispersão muito menor, quer dizer, os custos parecem menos sujeitos à redução para atender às necessidades.

Tabela 1 - Escolaridade dos pais (em \%)

\begin{tabular}{lcccc}
\hline \multirow{2}{*}{ ESCOLARIDADE } & \multicolumn{2}{c}{ DIREITO } & \multicolumn{2}{c}{ LICENCIATURAS } \\
& PAIS & MÃES & PAIS & MÃES \\
\hline Nenhuma escolaridade & 6,8 & 5,7 & 9,7 & 7,0 \\
Ensino Fundamental (1 $1^{\mathrm{a}}$ a 4 4 $^{\mathrm{a}}$ série) & 18,2 & 16,5 & 37,6 & 30,6 \\
Ensino Fundamental (5 a $^{\mathrm{a}}$ série) & 18,8 & 13,1 & 15,6 & 18,8 \\
Ensino Médio & 33,0 & 39,8 & 25,3 & 34,4 \\
Ensino Superior & 15,9 & 9,1 & 7,5 & 7,5 \\
Pós-graduação & 6,3 & 9,1 & 2,2 & 1,1 \\
Respostas em branco & 1,1 & 6,8 & 2,2 & 0,5 \\
TOTAL & 100,0 & 100,0 & 100,0 & 100,0 \\
\hline
\end{tabular}

Fonte: Pesquisa de campo (2011).

\section{Tabela 2 - Estimativa de custos diretos e indiretos de formação dos estudantes de Direito e de Licenciaturas}

\begin{tabular}{|c|c|c|c|c|c|}
\hline & \multicolumn{5}{|c|}{ LICENCIATURA } \\
\hline & $\begin{array}{c}\text { Média } \\
\text { semestral }(R \$)\end{array}$ & $\begin{array}{l}\text { Média total } \\
(\mathrm{R} \$)\end{array}$ & $\begin{array}{c}\text { Proporção em } \\
\text { relação aos } \\
\text { custos totais } \\
(\%)\end{array}$ & Desvio padrão & $\begin{array}{l}\text { Coeficiente } \\
\text { de variação }\end{array}$ \\
\hline $\begin{array}{r}\text { Mensalidade } \\
\text { escolar }\end{array}$ & $2.075,35$ & $14.049,51$ & 64,0 & $3.890,20$ & 0,28 \\
\hline $\begin{array}{r}\text { Material } \\
\text { escolar }\end{array}$ & 61,09 & 409,34 & 1,9 & 309,42 & 0,76 \\
\hline Livros & 92,65 & 648,42 & 3,0 & 807,47 & 1,25 \\
\hline Cópias & 172,97 & $1.160,40$ & 5,3 & 946,91 & 0,82 \\
\hline Lanches & 254,73 & $1.669,47$ & 7,6 & $1.287,54$ & 0,77 \\
\hline Transporte & 704,77 & $4.014,20$ & 18,3 & $5.880,19$ & 1,46 \\
\hline \multirow[t]{3}{*}{ TOTAL } & $3.361,55$ & $21.951,34$ & 100,0 & & \\
\hline & \multicolumn{5}{|c|}{ DIREITO } \\
\hline & $\begin{array}{c}\text { Média } \\
\text { semestral }(R \$)\end{array}$ & $\begin{array}{l}\text { Média total } \\
(\mathrm{R} \$)\end{array}$ & $\begin{array}{l}\text { Proporção em } \\
\text { relação aos } \\
\text { custos totais } \\
(\%)\end{array}$ & Desvio padrão & $\begin{array}{l}\text { Coeficiente } \\
\text { de variação }\end{array}$ \\
\hline $\begin{array}{r}\text { Mensalidade } \\
\text { escolar }\end{array}$ & $3.889,03$ & $38.890,35$ & 64,0 & $11.144,79$ & 0,29 \\
\hline $\begin{array}{r}\text { Material } \\
\text { escolar } \\
\end{array}$ & 76,99 & 769,94 & 1,3 & 893,18 & 1,16 \\
\hline Livros & 212,33 & $2.123,29$ & 3,5 & $1.806,08$ & 0,85 \\
\hline Cópias & 156,55 & $1.565,45$ & 2,6 & $3.342,20$ & 2,13 \\
\hline Lanches & 402,47 & $4.024,71$ & 6,6 & $4.200,66$ & 1,04 \\
\hline Transporte & $1.358,54$ & $13.426,55$ & 22,1 & $16.863,59$ & 1,26 \\
\hline TOTAL & $6.095,92$ & $60.800,29$ & 100,0 & & \\
\hline
\end{tabular}

Fonte: Pesquisa de campo (2011). Em valores nominais. 
No total, os custos das licenciaturas são quase a metade dos de Direito. Em correspondência com a renda, custam pouco mais da metade que Direito. Em conformidade com a sua capacidade financeira, as mensalidades são menores e os custos indiretos as acompanham. É possível que os futuros educadores "apostem" menos numa carreira financeiramente menos promissora, ao passo que os futuros bacharéis decidem "investir" mais em carreira mais rendosa. $\mathrm{O}$ prosseguimento da pesquisa longitudinal permitirá confirmar ou não.

No que concerne ao financiamento, $45,7 \%$ dos estudantes de licenciatura e $72,2 \%$ dos de Direito não contavam com bolsa ou ajuda. Coerente com o seu perfil socioeconômico, $36,0 \%$ dos primeiros contavam com bolsa externa, exceto o Fies e o Prouni, e 11,8\% recebiam bolsa integral ou parcial da própria IES, apesar de as mensalidades serem bem menores. No caso de Direito, apenas 4,5\% recebiam bolsa externa e 15,3\%, bolsa da IES. A proporção de beneficiados pelo Fies e Prouni foi reduzida e de pequena diferença entre os cursos: $3,3 \%$ dos estudantes de licenciaturas e 4,5\% dos discentes de Direito. Assim, por terem menor renda, os futuros licenciados, devido às dificuldades de arcar com custos bem menores, fizeram jus a um volume maior de ajuda financeira que os seus outros colegas. Verifica-se que os resultados de renda, custos e financiamento, coerentes entre si, evidenciam que é muito mais "barato" formar um educador que um bacharel em Direito. Custos baixos e retornos modestos significariam que o "barato" sai caro? Que esperam a sociedade e a economia dos seus futuros educadores? Se as expectativas de ganhos futuros e o capital cultural deles são modestos, não seria lícito esperar um preparo mais cuidadoso?

A partir da segunda metade do século XX, na "era de ouro", referente ao grande crescimento econômico experimentado pelo país e a ampliação das classes médias urbanas, começa a ser difundida a "promessa da escola como entidade integradora" (GENTILI, 2008). Assim, os pais acreditavam que a educação seria um poderoso instrumento para a ascensão social e, por isso, incentivavam seus descendentes a obter mais credenciais. Desse modo, a igualdade de acesso e a igualdade de oportunidades são transformadas em expressões sinônimas (OLIVEIRA, 2005). A tradição de associar diploma de educação superior a uma profissão regulamentada e a posições ocupacionais privilegiadas é uma tradição antiga na sociedade brasileira (DURHAM, 2005). Como afirma Carvalho (2004), para aquela geração, a educação era uma espécie de "passaporte" para cargos mais valorizados e melhor remunerados.

Outra característica relevante para a composição do perfil dos pesquisados foi referente à conclusão do ensino médio. Representam $86,0 \%$ dos licenciandos e $73,3 \%$ dos estudantes de Direito aqueles que cursaram todo o ensino médio 
(ou grande parte) na escola pública. Na escola privada, também completamente ou em sua maior parte, $22,2 \%$ dos alunos de Direito e $9,7 \%$ dos estudantes de Licenciatura. Essa informação demonstra que a seletividade escolar tem início antes mesmo do ingresso numa IES. A proporção de estudantes de Direito que haviam concluído o ensino médio em escolas particulares era superior ao dobro dos estudantes de Licenciaturas. Não se considera a qualidade de uma em detrimento da outra, mas as avaliações da educação básica no país reiteram que a média de desempenho discente é mais alta nas instituições particulares, enquanto o grupo familiar do aluno oriundo de escola particular tende a possuir renda superior à do aluno da escola pública.

Quanto à modalidade, cursaram o ensino médio regular 74,7\% dos licenciandos e $62,5 \%$ dos alunos de Direito. Concluíram o ensino médio em educação de jovens e adultos ou ensino supletivo $16,1 \%$ dos estudantes de Licenciatura e $19,3 \%$ dos alunos do curso de Direito. Em relação à época em que concluíram os estudos de ensino médio, apenas $16,7 \%$ dos alunos de Licenciatura e 20,5\% dos de Direito terminaram no ano anterior ao ano de ingresso na IES. Esse dado pode ser explicado pela quantidade de estudantes graduados cursando Direito.

Os aspectos culturais também foram considerados pela pesquisa. Na perspectiva de Bourdieu (2007b), o capital cultural e também o social, transmitidos hereditariamente, são determinantes no rendimento escolar e explicam grande parte das desigualdades sociais e escolares. O quadro 2 resume as características predominantes dos dois grupos pesquisados.

Em todos os aspectos culturais pesquisados, observa-se que os alunos de Direito aparecem como detentores de mais capital cultural que os estudantes dos cursos de formação de educadores.

\section{CONSIDERAÇÕES FINAIS}

Esta pesquisa teve o objetivo de comparar as características sociais, econômicas e culturais entre alunos ingressantes dos cursos de Licenciatura e de Direito, a fim de verificar se a ampliação do acesso à educação superior se traduziu efetivamente em democratização deste nível educacional ou se as diferenças entre cursos refletem em parte a estratificação social. Em se tratando de um estudo de caso, os resultados, ainda que sugestivos, não podem ser generalizados, mesmo reiterando a literatura.

O curso de Direito se caracterizou como mais seletivo e socialmente mais prestigioso. Seus estudantes apresentaram origens econômicas, sociais e culturais mais vantajosas para os critérios vigentes na sociedade que os futuros 


\section{Quadro 2 - Respostas predominantes em relação aos aspectos culturais dos grupos pesquisados}

\begin{tabular}{|c|c|c|}
\hline Característica & Alunos de Direito & Alunos de Licenciatura \\
\hline $\begin{array}{l}\text { Conhecimento de língua inglesa } \\
\text { (média em escala de } 1 \text { a } 5 \text {, em que } \\
1 \text { corresponde a conhecimento } \\
\text { nulo e } 5 \text { às habilidades de leitura, } \\
\text { fala e escrita da língua) }\end{array}$ & 2,3 & 1,9 \\
\hline $\begin{array}{l}\text { Conhecimento de língua espanhola } \\
\text { (média em escala de } 1 \text { a } 5 \text {, em que } \\
1 \text { corresponde a conhecimento } \\
\text { nulo e } 5 \text { às habilidades de leitura, } \\
\text { fala e escrita da língua) }\end{array}$ & 1,9 & 1,6 \\
\hline $\begin{array}{l}\text { Conhecimento de informática } \\
\text { (média em escala de } 1 \text { a } 4 \text {, em que } \\
1 \text { corresponde a "muito ruim" e } 4 \text { a } \\
\text { "muito bom") }\end{array}$ & 3,2 & 3,0 \\
\hline $\begin{array}{l}\text { Frequência de utilização do } \\
\text { computador }\end{array}$ & $\begin{array}{l}\text { Sempre: } 60,8 \% \text {; } \\
\text { frequentemente: } 31,8 \% .\end{array}$ & $\begin{array}{l}\text { Sempre: } 49,7 \% ; \\
\text { frequentemente: } 38,8 \% .\end{array}$ \\
\hline $\begin{array}{l}\text { Local de utilização do computador } \\
\text { (admitiam-se respostas múltiplas) }\end{array}$ & $\begin{array}{l}\text { Em casa: } 49,6 \% \\
\text { no trabalho: } 26,7 \% \text {. }\end{array}$ & $\begin{array}{l}\text { Em casa: } 50,8 \% \\
\text { no trabalho } 20,7 \%\end{array}$ \\
\hline $\begin{array}{l}\text { Finalidade de utilização do } \\
\text { computador (admitiam-se múltiplas } \\
\text { respostas) }\end{array}$ & $\begin{array}{l}\text { Trabalhos escolares: } 25,1 \% \text {; } \\
\text { comunicação via e-mail: } \\
\text { 20,8\%; } \\
\text { entretenimento: } 19,9 \% \text {. } \\
\end{array}$ & $\begin{array}{l}\text { Trabalhos escolares: } \\
\text { 30,2\%; comunicação via } \\
\text { e-mail: } 24,9 \% \text {; } \\
\text { entretenimento: } 21,3 \% \text {. } \\
\end{array}$ \\
\hline $\begin{array}{l}\text { Quantidade de livros lidos no } \\
\text { ano anterior, com exceção dos } \\
\text { escolares (média) }\end{array}$ & 3,8 & 3,2 \\
\hline $\begin{array}{l}\text { Tipo de livro mais lido (admitiam-se } \\
\text { respostas múltiplas) }\end{array}$ & $\begin{array}{l}\text { Obras literárias de ficção: } \\
27,5 \% \text {; } \\
\text { livros técnicos: } 21,8 \% \text {. }\end{array}$ & $\begin{array}{l}\text { Obras literárias de ficção: } \\
34,3 \% \text {; } \\
\text { livros religiosos, inclusive } \\
\text { a Bíblia e comentários: } \\
28,6 \% \text {. }\end{array}$ \\
\hline Frequência de leitura do jornal & $\begin{array}{l}\text { Algumas vezes por semana: } \\
36,4 \% \text {; diariamente: } 34,1 \% \text {. }\end{array}$ & $\begin{array}{l}\text { Algumas vezes por } \\
\text { semana: } 40,3 \% \text {; } \\
\text { raramente: } 23,7 \% \text {. }\end{array}$ \\
\hline $\begin{array}{l}\text { Assuntos mais lidos do jornal } \\
\text { (admitiam-se respostas múltiplas) }\end{array}$ & $\begin{array}{l}\text { Política e(ou) economia: } \\
25,4 \% \text {; } \\
\text { Ciência, saúde e(ou) } \\
\text { tecnologia: } 17,6 \% ; \\
\text { todos os assuntos: } 14,9 \% \text {. }\end{array}$ & $\begin{array}{l}\text { Cultura e(ou) arte: } \\
\text { 20,4\%; Ciência, saúde } \\
\text { e(ou) tecnologia: } 18,2 \% \text {; } \\
\text { política e(ou) economia: } \\
15,7 \% \text {. } \\
\end{array}$ \\
\hline $\begin{array}{l}\text { Meio mais utilizado para se manter } \\
\text { atualizado (admitiam-se respostas } \\
\text { múltiplas) }\end{array}$ & $\begin{array}{l}\text { Internet: } 44,3 \% \text {; } \\
\text { TV: } 23,1 \%\end{array}$ & $\begin{array}{l}\text { Internet: } 38,4 \% \\
\text { TV: } 28,1 \% \text {. }\end{array}$ \\
\hline $\begin{array}{l}\text { Preferências artístico-culturais } \\
\text { (admitiam-se respostas múltiplas) }\end{array}$ & $\begin{array}{l}\text { Cinema: } 43,0 \% ; \\
\text { Show musicais e(ou) } \\
\text { concertos: } 22,3 \% \text {. }\end{array}$ & $\begin{array}{l}\text { Cinema: } 48,5 \% \\
\text { Show musicais e(ou) } \\
\text { concertos: } 20,8 \% \text {. } \\
\end{array}$ \\
\hline
\end{tabular}

Fonte: Pesquisa de campo (2011). 
educadores. Certas linhas da estratificação social são reforçadas na medida em que os rios continuam a correr para o mar: estabelecida uma hierarquia de IES e de cursos, os candidatos de nível socioeconômico mais favorável tendem a ingressar nos mais "promissores". Com os demais, a tendência é o contrário, sugerindo uma autolimitação, a partir da avaliação das suas possibilidades. Essa distribuição, entretanto, não constitui uma originalidade brasileira: o aumento substancial de concluintes do ensino secundário na França levou à limitada democratização da educação superior (DURU-BELLAT; KIEFFER, 2008), numa hierarquia retratada pela nossa expressão popular "cada macaco no seu galho", isto é, no galho de que se considera "merecedor", conforme os padrões sociais. O mesmo tem ocorrido nos Estados Unidos (KARABEL, 1978), onde a "orientação" das escolas, como na França, "amansa" os alunos, dirigindo-os aos nichos que the parecem mais apropriados.

Entretanto, cabe o princípio do contraditório. Se os futuros educadores ficam por "baixo" no que se refere a estas condições, inclusive e especialmente o capital cultural, é lícito supor que a sua atuação tenderá a ficar comprometida, gerando efeitos multiplicativos desfavoráveis. Ou, questionando o que é "baixo" e "alto" na ordem social, tais futuros educadores teriam mais possibilidades de comunicar-se com alunos que se situam em posições também menos privilegiadas? Ou, ainda, ao longo do curso eles terão a capacidade de pisar o acelerador mais fundo e alcançar o que antes não teriam alcançado? Como esta é parte de uma pesquisa longitudinal, só o acompanhamento desta coorte até pelo menos a conclusão de curso, poderá responder a esta e a outras questões.

\section{REFERÊNCIAS}

AZEVEDO, Fernando de. A cultura brasileira. 6. ed. Rio de Janeiro: UFRJ, 1996.

BARREYRO, Gladys Beatriz. Mapa do ensino superior privado. Brasília: INEP, 2008.

BORGES, José Leopoldino das Graças; CARNIELLI, Beatrice Laura. Educação e estratificação social no acesso à universidade pública.

Cadernos de Pesquisa, São Paulo, v. 35, n. 124, p. 113-139, jan./abr. 2005. 
BOURDIEU, Pierre. A Escola conservadora: as desigualdades frente à escola e à cultura. Tradução de Aparecida Joly Gouveia. In: NOGUEIRA, Maria Alice; CATANI, Afrânio (Org.). Escritos de educaçáo. 9. ed. Petrópolis: Vozes, 2007a.

. Os três estados do capital cultural. Tradução de Magali de Castro. In: NOGUEIRA, Maria Alice; CATANI, Afrânio (Org.). Escritos de educaçáo. 9. ed. Petrópolis: Vozes, 2007b. - Classificação, desclassificação, reclassificação. Tradução de Denice Barbara Catani. In: NOGUEIRA, Maria Alice; CATANI, Afrânio (Org.). Escritos de educaçáo. 9. ed. Petrópolis: Vozes, 2007c.

BRAGA, Mauro Mendes; PEIXOTO, Maria do Carmo L.; BOGUTCHI, Tânia F. Tendências da demanda pelo ensino superior: estudo de caso da UFMG. Cadernos de Pesquisa, Sáo Paulo, n. 113, p. 129-152, jul. 2001.

BRASIL. Lei 10.172, de 9 de janeiro de 2001. Aprova o Plano Nacional de Educação e dá outras providências. Diário Oficial da Uniáo. Brasília, DF, 10 jan. 2001. Disponível em: <http://www.planalto. gov.br/ccivil_03/leis/leis_2001/110172.htm> Acesso em: 19 jul. 2011.

BRITO, Márcia Regina F. ENADE 2005: perfil, desempenho e razão da opção dos estudantes pelas licenciaturas. Avaliaçáo, Campinas; Sorocaba, v. 12, n. 3, p. 401-443, set. 2007.

CARVALHO, Cynthia Paes. Projetos familiares e formação universitária: diploma e trajetórias sociais em tempos de crise e globalização. Cadernos CRH, Salvador, v. 17, n. 41, p. 79-90, maio/ago. 2004.

COELHO, Edmundo Campos. As profissóes imperiais: medicina, engenharia e advocacia no Rio de Janeiro, 1822-1930. Rio de Janeiro: Record, 1999.

CORADINI, Odaci Luiz. Titulação escolar, condição de "elite" e posição social. Revista Brasileira de Educaçáo, Rio de Janeiro, v. 15, n. 43, p. 45-69, jan./abr. 2010.

DIAS SOBRINHO, José. Democratização, qualidade e crise da educação superior: faces da exclusão e limites da inclusão. Educação e Sociedade, Campinas, v. 31, n. 113, p. 1223-1245, out./dez. 2010. 
DINIZ, Marli. Os donos do saber: profissóes e monopólios profissionais. Rio de Janeiro: Revan, 2001.

DINIZ-PEREIRA, Júlio Emílio. O ovo ou a galinha: a crise da profissão docente e a aparente falta de perspectiva para a educação brasileira.

Revista Brasileira de Estudos Pedagógicos, Brasília, v. 92, n. 230, p. 34-51, jan./abr. 2011.

DURHAM, Eunice R. Educação superior, pública e privada (18082000). In: SCHWARTZMAN, Simon; BROCK, Colin (Org.). Os desafios da educaçáo no Brasil. Rio de Janeiro: Nova Fronteira, 2005.

DURU-BELLAT, Marie. L'inflation scolaire: les désillusions de la méritocratie. Paris : Du Seuil, 2006.

DURU-BELLAT, Marie; KIEFFER, Annick. Du baccalauréat à l'enseignement supérieur en France : déplacement et recomposition des inégalités. Population, Paris, v. 63, n. 1, p. 123-157, 2008. Disponível em : <http://www. cairn.info/revue-population-2008-1-page-123.htm>. Acesso em: 28 ago. 2011.

ESTEVE, José M. Mudanças sociais e função docente. In: NÓVOA, António (Org.). Profissáo professor. Porto: Porto, 1999.

GATTI, Bernadete Angelina; BARRETO, Elba Siqueira de Sá (Coord.). Professores do Brasil: impasses e desafios. Brasília: UNESCO, 2009.

GENTILI, Pablo. Educar para o desemprego: a desintegração da promessa integradora. In: FRIGOTTO, Gaudêncio (Org.). Educaçáo e crise do trabalho: perspectivas de final de século. 9. ed. Petrópolis: Vozes, 2008.

GOMES, Candido Alberto. Curso superior e mobilidade social: vale a pena? Educaçáo Brasileira, Brasília, v. 10, n. 20, p. 63-84, 1 sem. 1988. Paulo: EPU, 2005.

. A educação em novas perspectivas sociológicas. 4. ed. São

. O Brasil e seus futuros. Brasília: SENAI, 2010a.

. Ensino Médio obrigatório: que impactos? Estudos em avaliaçáo educacional. São Paulo, v. 21, n. 46, p. 319-340, mai./ago. 2010 b. 
et al. Educação e trabalho: representaçôes de professores e alunos do ensino médio. Ensaio: avaliação e políticas públicas em Educação, Rio de Janeiro, v. 14, n. 50, p. 11-26, jan./mar. 2006.

GOUVEIA, Aparecida Joly. Professoras de amanhá: um estudo de escolha ocupacional. 2. ed. São Paulo: Pioneira, 1970.

. Democratização do ensino e oportunidades de emprego. São Paulo: Loyola, 1981.

INSTITUTO BRASILEIRO DE GEOGRAFIA E ESTATÍSTICA IBGE. Síntese de indicadores sociais: uma análise das condiçôes de vida da população brasileira. Rio de Janeiro: IBGE, 2008. (Série Estudos e Pesquisas: Informação Demográfica e Socioeconômica, n. 23).

INSTITUTO NACIONAL DE ESTUDOS E PESQUISAS EDUCACIONAIS ANÍSIO TEIXEIRA - INEP. Evolução da educaçáo superior - Graduação - Anos 1980-1998. Brasília, [1999?] Disponível em: <http://portal.inep.gov.br/web/censo-da-educacao-superior/ evolucao-1980-a-2007>. Acesso em: 18 jul. 2011.

. Evoluçáo da educação superior - Graduação - Anos 19912007. Brasília, [2008?] Disponível em: <http://portal.inep.gov.br/web/ censo-da-educacao-superior/evolucao-1980-a-2007>. Acesso em: 18 jul. 2011.

. Sinopse da educação superior 2008. Brasília, 2009a.

Disponível em: <http://portal.inep.gov.br/superior-censosuperiorsinopse>. Acesso em: 26 ago. 2011.

. Sinopse da educação superior 2009. Brasília, 2011. Disponível em: $<$ http://portal.inep.gov.br/superior-censosuperior-sinopse>. Acesso em: 26 ago. 2011.

Resumo técnico: Censo da Educação Superior 2008 (dados preliminares). Brasília: INEP, 2009b.

Resumo técnico: Censo da Educação Superior de 2009. Brasília: INEP, 2010.

JESUS, Saul Neves de. Desmotivação e crise de identidade na profissão docente. Katálysis, Florianópolis, v. 7, n. 2, p. 192-202, jul./dez. 2004. 
KARABEL, Jerome. Community colleges and social stratification: submerged class conflict in higher education. In: KARAEBEL, Jerome; HALSEY, A.H. Power and ideology in education. Nova Iorque: Oxford, 1978. p. 232-253.

LOUZANO, Paula et. al. Quem quer ser professor? Atratividade, seleção e formação docente no Brasil. Estudos em Avaliaçáo Educacional, São Paulo, v. 21, n. 47, p. 543-568, set./dez. 2010.

MERCADANTE, Paulo. A consciência conservadora no Brasil: contribuição ao estudo da formação brasileira. Rio de Janeiro: Saga, 1965.

MOEHLECKE, Sabrina; CATANI, Afrânio Mendes. Reforma e Expansão do Acesso ao Ensino Superior: balanços e proposiçóes. In: OLIVEIRA, João Ferreira et al. Políticas de acesso e expansão da educaçáo superior: concepçóes e desafios. Brasília: INEP, 2006. (Série Documental. Textos para discussão n. 23).

NAVARRO, Juan Carlos. El docente latinoamericano: carrera, incentivos y desempeño. In: (Ed.). ¿Quiénes son los maestros?: Carreras e incentivos docentes en América Latina. Washington, D.C.: Banco Interamericano de Desarrollo, 2002. p. 1-47.

NOGUEIRA, Maria Alice; AGUIAR, Andrea Moura de Souza; RAMOS, Viviane Coelho Caldeira. Fronteiras desafiadas: a internacionalização das experiências escolares. Educaçáo e Sociedade, Campinas, v. 29, n. 103, p. 355-376, maio/ago. 2008.

NÓVOA, António. O passado e o presente dos professores. In: (Org.). Profissáo professor. Porto: Porto, 1999. p. 13-34.

. Os professores e o "novo" espaço público da educação. In: TARDIF, Maurice; LESSARD, Claude (Org.). O ofício de professor: história, perspectivas e desafios internacionais. 3. ed. Petrópolis: Vozes, 2009. p. 217-233.

NERI, Marcelo Cortes (Coord.). Você no mercado de trabalho. Rio de Janeiro: FGV/IBRE, CPS, 2008. Disponível em: <http://www.fgv.br/cps/ iv/>. Acesso em: 25 jul. 2011.

OLIVEIRA, João Batista de Araújo e. Desigualdade e políticas compensatórias. In: SCHWARTZMAN, Simon; BROCK, Colin (Org). 
Os desafios da educaçáo no Brasil. Rio de Janeiro: Nova Fronteira, 2005.

PEUGNY, Camille. Le déclassement. Paris: Grasset \& Fasquelle, 2009.

RAMA, Germán W.; NAVARRO, Juan Carlos. Carreira dos professores na América Latina. In: FUNDAÇÃO VICTOR CIVITA. O

desempenho dos professores na América Latina e no Caribe: novas prioridades. São Paulo: Fundação Victor Civita, 2004. p. 303-323.

RIBEIRO, Sergio Costa; KLEIN, Ruben. A divisão interna da universidade: posição social das carreiras. Educação e Seleção, São Paulo, n. 5, p. 29-36, jan./jun. 1982.

SCHWARTZMAN, Simon. Pobreza, exclusão social e modernidade: uma introdução ao mundo contemporâneo. São Paulo: Augurium, 2004.

SETTON, Maria da Graça Jacintho. A divisão interna do campo universitário: uma tentativa de classificação. Revista Brasileira de Estudos Pedagógicos, Brasília, v. 80, n. 196, p. 451-471, set./dez. 1999.

SINGER, Paul. Diploma, profissão e estrutura social. In: CATANI, Denice Bárbara et al. (Org.). Universidade, escola e formação de professores. São Paulo: Brasiliense, 1986.

SOUSA NETO, Manoel Fernandes de. O ofício, a oficina e a profissão: reflexóes sobre o lugar social do professor. Cadernos Cedes, Campinas, v. 25, n. 66, p. 249-259, maio/ago. 2005.

TARDIF, Maurice; LESSARD, Claude. O trabalho docente: elementos para uma teoria da docência como profissão de interaçóes humanas. Tradução de João Batista Kreuch. 5. ed. Petrópolis: Vozes, 2009.

TARTUCE, Gisela Lobo B. P.; NUNES, Marina M. R.; ALMEIDA, Patrícia Cristina Albieri de. Alunos do ensino médio e atratividade da carreira docente no Brasil. Cadernos de Pesquisa, São Paulo, v. 40, n. 140, p. 445-477, maio/ago. 2010.

UNESCO. O perfil dos professores brasileiros: o que fazem, o que pensam, o que almejam. São Paulo: Moderna, 2004. 
VAILLANT, Denise. Construção da profissão docente na América Latina: tendências, temas e debates. PREAL. Documento no 31, 2004. Disponível em <www.preal.org/Archivos/Bajar.asp?Carpeta=Preal Publicaciones/PREAL Documentos/\&Archivo=Preal_Doc31.pdf $>$. Acesso em: 21 set. 2010.

VARGAS, Hustana Maria. Sem perder a majestade: "profissóes imperiais" no Brasil. Estudos de Sociologia, Araraquara, v. 15, n. 28, p. 107-124, 2010. 